\title{
A INFLUÊNCIA DO AMBIENTE DA PRÁTICA PROFISSIONAL DA ENFERMAGEM NOS RESULTADOS COM PACIENTES, PROFISSIONAIS E INSTITUIÇÕES
}

\author{
Kamila Mariana Adami Carvalho*, Vanessa Abreu da Silva, Renata C. Gasparino
}

\begin{abstract}
Resumo
Objetivo: avaliar a presença de características do ambiente de trabalho que favorecem a prática profissional da enfermagem e sua relação com os resultados com pacientes, profissionais e instituição. Método: estudo descritivo, transversal e quantitativo realizado em um hospital quaternário do interior do estado de São Paulo com 525 profissionais de enfermagem. Foram utilizados os instrumentos: Practice Environment Scale (PES) - Versão Brasileira, subescala exaustão emocional do Inventário de Burnout de Maslach (IBM) e as subescalas satisfação profissional e clima de segurança do Questionário Atitudes de Segurança (SAQ) Short Form. Resultados: os participantes mostraram uma percepção positiva em relação à comunicação entre equipes médica e de enfermagem, fundamentos de enfermagem voltados para a qualidade do cuidado e gestão competente. A equipe presta um cuidado qualificado, possui nível médio de exaustão emocional, baixa intenção de abandonar o emprego e percebe um baixo clima de segurança. $\mathrm{Na}$ correlação entre as variáveis, notou-se que a presença de características que favorecem a prática profissional da enfermagem influencia positivamente os resultados. Conclusão: o ambiente pode ser considerado misto para a prática da enfermagem e os achados mostram que melhorias realizadas no ambiente podem contribuir para melhores resultados com pacientes, profissionais e instituição.
\end{abstract}

\section{Palavras-chave:}

Ambiente de Instituições de Saúde; Enfermagem; Segurança do Paciente; Exaustão Profissional.

\section{Introdução}

A presença de características no ambiente de trabalho que favorecem a prática profissional da enfermagem podem contribuir para resultados favoráveis ${ }^{1}$. Diante do exposto, 0 objetivo do presente estudo foi avaliar a presença de características do ambiente de trabalho que favorecem a prática profissional da enfermagem e sua relação com os resultados com pacientes, profissionais e instituições.

\section{Método}

Estudo transversal e correlacional, realizado em um hospital público e de ensino do interior do estado de São Paulo. Participaram 525 profissionais de enfermagem que prestavam atendimento direto ao paciente e trabalhavam na unidade há mais de três meses. Os resultados com os pacientes foram avaliados por meio da percepção da qualidade da assistência prestada e clima de segurança; com os profissionais por meio da percepção sobre a exaustão emocional e satisfação com o trabalho e com relação à instituição, o resultado foi avaliado por meio da intenção do profissional deixar seu emprego no próximo ano.

\section{Resultados e Discussão}

A maioria da amostra era do sexo feminino $(75,1 \%)$, casada $(52,7 \%)$, técnica de enfermagem $(72,6 \%)$ e com apenas um vínculo empregatício $(75,1 \%)$. A idade média dos profissionais foi de 40,0 anos (dp $\pm 9,3$ ), o tempo médio de experiência na profissão de 14,0 anos (dp \pm 8,3), o tempo médio de trabalho na unidade de 8,2 anos $(\mathrm{dp} \pm 7,0)$ e o número médio de pacientes sob a responsabilidade do profissional de 7,2 (dp $\pm 6,1)$. Com relação a percepção da qualidade do cuidado, a média apresentada foi de 7,7 (dp $\pm 1,6)$ e a intenção de deixar o emprego no próximo ano de 1,9 (dp $\pm 3,3)$.

Tabela 1. Percepção das características do ambiente da prática, exaustão emocional, satisfação profissional e clima de segurança. Campinas, 2018.

\begin{tabular}{clcc}
\hline Instrumento & \multicolumn{1}{c}{ Subescalas } & Média & DP \\
\hline \multirow{4}{*}{ PES } & Relações & 2,8 & 0,6 \\
& Fundamentos para a qualidade & 2,6 & 0,6 \\
& Habilidade da gestão & 2,6 & 0,7 \\
& Adequação de recursos & 2,3 & 0,7 \\
\multirow{2}{*}{ IBM } & Assuntos hospitalares & 2,3 & 0,7 \\
\multirow{2}{*}{ SAQ } & Exaustão emocional & 22,0 & 7,0 \\
& Satisfação no trabalho & 77,9 & 17,4 \\
& Clima de segurança & 60,2 & 18,5 \\
\hline
\end{tabular}

Tabela 2. Coeficiente de correlação Spearman entre as subescalas da PES com as subescalas exaustão emocional do IBM, satisfação profissional e clima de segurança do SAQ e as variáveis percepção da qualidade do cuidado e intenção de sair do emprego. Campinas, 2018.

\begin{tabular}{|c|c|c|c|c|c|}
\hline $\begin{array}{c}\text { Subescalas } \\
\text { PES }\end{array}$ & 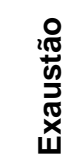 & 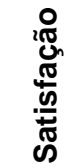 & 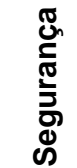 & $\begin{array}{l}\frac{0}{0} \\
\frac{0}{0} \\
\frac{0}{0} \\
\stackrel{0}{0}\end{array}$ & 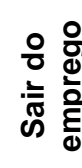 \\
\hline Participação & $-0,4^{*}$ & $0,4^{*}$ & $0,5^{*}$ & $0,3^{*}$ & $-0,2^{*}$ \\
\hline Qualidade & $-0,4^{*}$ & $0,4^{*}$ & $0,6^{*}$ & $0,4^{*}$ & $-0,1^{* *}$ \\
\hline Gestão & $-0,5^{\star}$ & $0,4^{*}$ & $0,6^{*}$ & $0,3^{*}$ & $-0,2^{\star *}$ \\
\hline Recursos & $-0,4^{*}$ & $0,3^{*}$ & $0,4^{*}$ & $0,4^{*}$ & $-0,1^{* *}$ \\
\hline Relações & $-0,4^{*}$ & $0,4^{*}$ & $0,4^{*}$ & $0,3^{*}$ & $-0,1^{* *}$ \\
\hline
\end{tabular}

\section{Conclusões}

O ambiente da instituição estudada pode ser considerado misto e melhorias no ambiente contribuem para obtenção de resultados mais favoráveis pacientes, profissionais e instituições.

\section{Agradecimentos}

Fundo de Apoio ao Ensino, Pesquisa e Extensão.

1. Lake ET. Development of the Practice Environment Scale of the Nursing Work Index. Res. nurs. health 2002;25:176-88. 